\title{
Tachycardia Related Cardiomyopathy: Response to Control of the Arrhythmia
}

\author{
BURT I. BROMBERG, M.D., MACDONALD DICK II, M.D., A. REBECCA SNIDER, M.D., \\ WILLIAM A. SCOTT, M.D., GERALD A. SERWER, M.D., EDWARD L. BOVE, M.D., \\ and KATHLEEN P. HEIDELBERGER, M.D.
}

From the Division of Pediatric Cardiology, C.S. Mott Children's Hospital, and the

Departments of Pediatrics, Surgery, and Pathology, University of Michigan, Ann Arbor, Michigan

\begin{abstract}
To evaluate the clinical response of five children with automatic atrial tachycardia (AAT) and associated cardiomyopathy to arrhythmia control, we compared pretreatment and posttreatment 24hour ECG heart rates, cardiothoracic ratio by chest radiograph, and echocardiographic measures of ventricular function. Two children were treated with amiodarone, two with surgical excision and cryoablation of the ectopic focus, and one with digoxin alone. Significantly slower mean heart rates were achieved, along with a dominant sinus rhythm and improvement in symptoms. Control of the $A A T$ resulted in improved mean cardiothoracic ratio ( 0.53 pre vs 0.49 post; $P$ $=0.02$ ), as well as improvement in a number of echocardiographic measurements: mean shorten-
\end{abstract}

\section{Introduction}

Supraventricular tachycardia (SVT) from an ectopic automatic atrial focus, herein called auto-

Presented, in part, at the 37th Annual Scientific Sessions, American College of Cardiology, Atlanta, 1988.

Drs. Bromberg and Scott were supported, in part, by fellowships from the American Heart Association of Michigan.

Address for reprints: Macdonald Dick II, MD, C.S. Mott Children's Hospital, Room F1126, Box 0204, University of Michigan Medical Center, 1500 East Medical Center Drive, Ann Arbor, MI 48109-0204.

Submitted for publication December 26, 1989; accepted with revisions January 30, 1990; revisions received February 7 , 1990. ing fraction (20\% pre vs $34 \%$ post; $P=0.006$ ), mean ejection fraction $(36 \%$ pre vs $50 \%$ post; $P$ $<0.01)$, mean velocity of circumferential fiber shortening (0.62 pre vs 1.20 post; $P=0.003$ ). Mean E-point septal separation corrected for enddiastolic dimension also showed a trend toward improvement $(0.25$ pre vs 0.16 post; $P=0.11)$. Right ventricular endocardial biopsies in four were nonspecific; an atrial biopsy from surgery showed a Purkinje fiber-like tissue in one patient, but was nonspecific in another. We conclude that cardiomyopathy can be causally linked to automatic atrial tachycardia and that aggressive medical and/or surgical management is warranted in those patients with signs and symptoms of impaired ventricular function. (J Interven Cardiol 1989:2:4)

matic atrial tachycardia (AAT), accounts for $<10 \%$ of SVT in children ${ }^{1,2}$ is usually slower than the more common reentrant forms of SVT, and may be virtually incessant. At one time considered benign $^{3-5} \mathrm{AAT}$, in the absence of structural heart disease, has recently been associated with cardiomyopathy $(\mathrm{CM})$. Although AAT is often refractory to conventional medical therapy, several reports suggest that control of the arrhythmia improves cardiac performance. ${ }^{6,7}$ In recent years, new pharmacologic agents ${ }^{8-11}$ as well as surgical exci$\operatorname{sion}^{12-19}$ and catheter electrical ablation ${ }^{20-22}$ have led to successful control of intractable AAT. To further examine the proposition that control of persistent AAT favorably alters cardiac function in some patients with cardiomyopathy, we compared the clinical course and noninvasive measures of 


\section{BROMBERG, ET AL.}

ventricular function before and after therapy in five children with AAT. In addition, the findings of two right atrial and three right ventricular biopsies obtained from these patients are summarized. Recommendations for treatment based on this experience are outlined.

\section{Methods}

Five patients referred to the Pediatric Arrhythmia Clinic at C.S. Mott Children's Hospital, University of Michigan, exhibited poorly controlled, virtually incessant SVT (Fig. 1) and had developed fatigue, exercise intolerance, increased heart size on chest radiograph, and echocardiographic findings of decreased ventricular function, suggestive of cardiomyopathy. Four patients underwent electrophysiologic study (EPS) using programmed extrastimulation (PES), overdrive pacing, and mapping of atrial activation during the tachycardia. Four patients had hemodynamic study and two right ventricular endomyocardial biopsy; one had a right ventricular biopsy and two atrial biopsies at surgery. The diagnosis of automatic atrial tachycardia (AAT) was based upon the criteria of Goldreyer $^{23}$ et al. and others ${ }^{24,25}$ [initiation of the tachycardia by spontancous atrial depolarizations identical to successive atrial depolarizations during the tachycardia, independence of the tachycardia cycle length on AV node conduction, succes- sive shortening of the tachycardia cycle length after the initial several beats ("warm up"), atrial depolarization during the tachycardia that reset the atrial cycle, and failure of a single or a train of atrial premature depolarizations to initiate or interrupt the tachycardia]. In one patient the diagnosis was made by the surface ECG and Holter tracings alone (initiating $P$ wave of the tachycardia as the same morphology of the subsequent beats, "warm-up" period, and atrioventricular dissociation during SVT). Persistent junctional reciprocating tachycardia was excluded by either the absence of $1: 1$ atrioventricular conduction during the tachycardia or the absence of ventriculoatrial conduction during ventricular pacing as well. The selection of medical or surgical treatment was based upon the duration of the patient's symptoms, their anticipated compliance with a medical regimen, and, in two patients, their decision against chronic antiarrhythmic medication.

Response to therapy was evaluated by pre- and posttreatment 24-hour ambulatory electrocardiographic tracings (CardioData Corp., Northboro, MA, USA), chest radiographs, and two-dimensional and M-mode echocardiograms (Advanced Technology Laborotories, Seattle, WA, USA and/ or Acuson Computer Sonography, Mountain View, CA, USA). All five patients were free of valvular, congenital, ischemic or other structural heart disease by two-dimensional echocardiogram, Doppler analysis, and cineangiography (four pa-
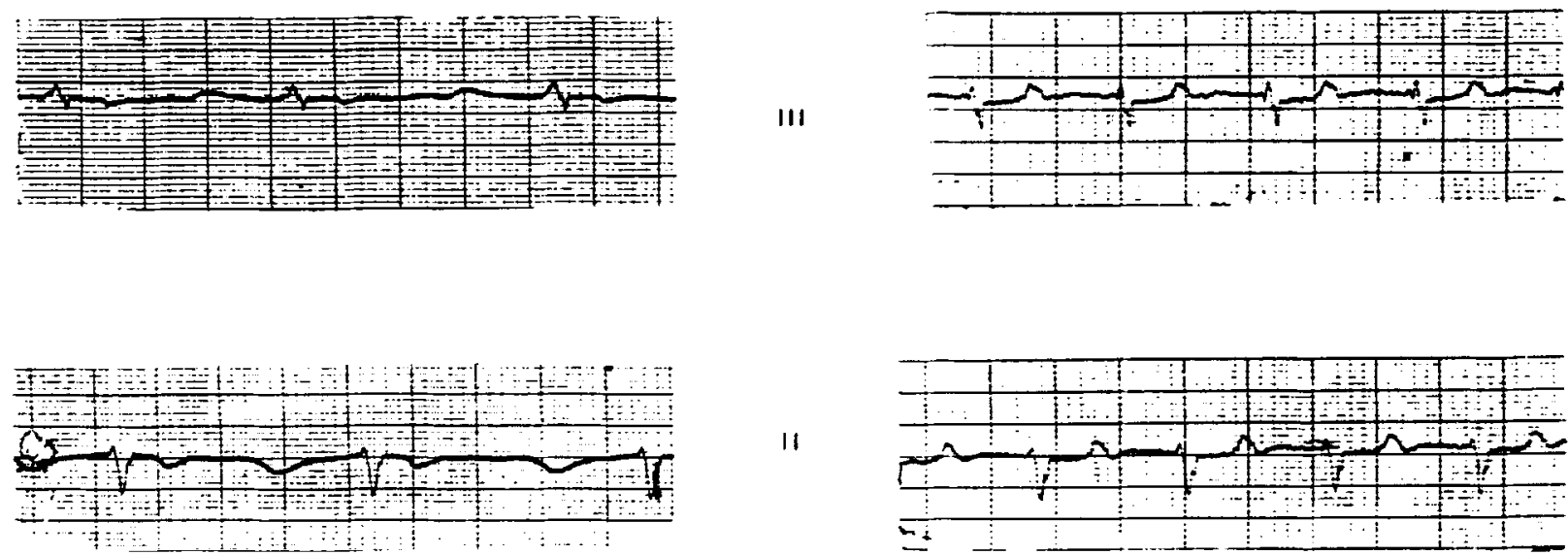

Figure 1. Representative ECG tracings from leads II and III from patient $\# 4$ before and after final treatment. Note the pre-treatment heart rate of $125 \mathrm{bpm}$ and the inverted $P$ waves in both leads (left hand tracings). Following treatment the rate is 75 bpm and the $P$ waves are upright in both leads (right hand tracings). 
tients). Cardiac rhythm and mean 24-hour heart rates were determined by computer generated analysis and confirmed by full disclosure tracings. The cardiothoracic ratio (CTR) was measured from the chest radiograph in the posterior-anterior projection during maximal inspiration. The left ventricular shortening fraction (SF), mean velocity of circumferential fiber shortening corrected for heart rate $\left(\mathrm{VCF}_{\mathrm{c}}\right), \mathrm{E}$-point septal separation normalized for end-diastolic demension (EPSS/ EDD) were measured from the M-mode echocardiogram; the left ventricular ejection fraction (EF) determined from the apical four-chamber view of the two-dimensional echocardiogram was calculated using the Simpson's rule algorithm. All pretreatment studies were obtained within 1 week prior to initiation of therapy. The mean interval between pre- and posttreatment examination was 1.5 years. Results are expressed as the mean \pm one standard deviation and are compared using a paired $t$-test. Differences in the mean were considered significant when the $P$ value was $\leq 0.05$.

\section{Results}

Symptoms. The clinical data are summarized in Table I. All patients complained of easy fatigabil- ity, two noted dizziness, and one had exercise intolerance. Electrophysiological study in four patients localized the origin of the AAT at the coronary sinus os in two patients and the low septal right atrium in one. In the fourth patient, earliest atrial activation during SVT occurred both at the mouth of the coronary sinus and the atrioventricular node, suggesting that the abnormal impulse arose equidistant between these two points. Hemodynamic studies in the four patients undergoing electrophysiologic study demonstrated a mean left ventricular end-diastolic pressure (LVEDP) of $16 \mathrm{mmHg}$ (range $10-26 \mathrm{mmHg}$ ), and a mean cardiac index of $2.8 / \mathrm{min} / \mathrm{m}^{2}$ (range $1.6-3.2$ $\mathrm{L} / \mathrm{min} / \mathrm{m}^{2}$ ).

Treatment. An average of 2.3 drug trials were used in three patients before satisfactory control of the AAT was achieved (Table I). Digoxin alone provided adequate control in only one patient. Beta blockade was ineffective in the two patients in whom it was tried. Two patients, ages 9 and 11 years, received amiodarone therapy for control of the SVT. After initial success with amiodarone, atrioventricular block occurred in one of these patients. Amiodarone was withdrawn and flecainide initiated with a return of control of the tachycardia. The remaining two patients, ages 15 and 20 years, who had received digoxin and propranolol

Table I. Clinical, Therapeutic, Biopsy, and Follow-up Data

\begin{tabular}{|c|c|c|c|c|c|c|c|c|c|c|}
\hline Patient & $\begin{array}{l}\text { Current } \\
\text { Age }\end{array}$ & $\begin{array}{l}\text { Duration } \\
\text { of SVT }\end{array}$ & $\begin{array}{c}\text { SVT } \\
\text { Heart } \\
\text { Rate } \\
(b p m)\end{array}$ & Symptoms & $\begin{array}{c}\text { Early } \\
\text { Treatment }\end{array}$ & $\begin{array}{c}\text { Duration of } \\
\text { Conventional } \\
\text { Therapy }\end{array}$ & $\begin{array}{c}\text { Subsequent } \\
\text { Treatment }\end{array}$ & $\begin{array}{c}\text { Myocardial } \\
\text { Biopsy }\end{array}$ & Outcome & $\begin{array}{c}\text { Duration of } \\
\text { Subsequent } \\
\text { Treatment }\end{array}$ \\
\hline 1 & 9.3 years & 3.5 years & 140 & $\begin{array}{l}\text { fatigue, } \\
\text { dizziness }\end{array}$ & $\begin{array}{l}\text { digoxin } \\
\text { verapamil } \\
\text { flecainide }\end{array}$ & 2 years & amiodarone & Not available & NSR & 1.5 years \\
\hline 2 & 9.8 years & 0.6 years & 135 & fatigue & $\begin{array}{l}\text { digoxin } \\
\text { flecainide }\end{array}$ & 0.5 year & $\begin{array}{l}\text { amiodarone } \\
\text { flecainide }\end{array}$ & $\begin{array}{l}\text { R Vent: } \\
\text { Normal }\end{array}$ & $\begin{array}{l}90 \% \text { NSR } \\
10 \% \text { SVT }\end{array}$ & $\begin{array}{l}1.0 \text { year } \\
0.5 \text { year }\end{array}$ \\
\hline 3 & 11.3 years & 0.1 year & 175 & fatigue, dyspnea & digoxin & - & digoxin & $\begin{array}{l}\text { R Vent: } \\
\text { Normal }\end{array}$ & NSR & 1.0 year \\
\hline 4 & 14.1 years & 13.8 years & 130 & $\begin{array}{l}\text { fatigue, } \\
\text { dizziness }\end{array}$ & digoxin & 13 years & $\begin{array}{l}\text { cryoablation/ } \\
\text { digoxin }\end{array}$ & $\begin{array}{l}\text { R Atrium: } \\
\text { Normal }\end{array}$ & $\begin{array}{l}60 \% \text { NSR } \\
40 \% \text { SVT }\end{array}$ & 3 years \\
\hline 5 & 19.5 years & 13.5 years & 135 & $\begin{array}{l}\text { fatigue, exercise } \\
\text { intolerance }\end{array}$ & $\begin{array}{l}\text { digoxin } \\
\text { nadolol } \\
\text { quinidine } \\
\text { propranolol }\end{array}$ & 8 years & $\begin{array}{l}\text { cryoablation/ } \\
\text { excision }\end{array}$ & $\begin{array}{l}\text { R Atrium: } \\
\text { Purkinje- } \\
\text { like Fibers } \\
\text { RAA: } \\
\text { Purkinje- } \\
\text { like Fibers } \\
\text { R Vent: } \\
\text { Normal }\end{array}$ & $\begin{array}{l}\text { NSR } \\
\text { RARE APB }\end{array}$ & 3 years \\
\hline
\end{tabular}

APB = atrial premature beat; bpm = beats per minute; NSR = normal sinus rhythm; $\mathrm{R}=$ right; RAA $=$ right atrial appendage; SVT $=$ supraventricular tachycardia; Vent $=$ ventricle. 
either alone or together for greater than 13 years, elected surgery. The five patients have been followed for an average of 1.5 years.

Heart Rate and Cardiothoracic Ratio. There was a significant $(\mathrm{P} \leq 0.002)$ reduction in the mean heart rate $(128 \pm 24$ vs $91 \pm 10 \mathrm{bpm})$ as determined by 24-hour ambulatory electrocardiograms. The dominant mechanism of the post-treatment cardiac rhythm was sinus (Fig. 1) in all five patients. Patients 1-3 were treated medically, and each required adjustments of the medication, including other antiarrhythmia trials, for satisfactory control (a few isolated atrial premature beats). $\mathrm{Pa}$ tient 4 had marked reduction in the incidence and persistence of SVT but still had runs of tachycardia. Patient 5 is virtually free of arrhythmia with only a few isolated atrial premature beats and a normal heart rate response to treadmill exercise (i.e., no ectopic tachycardia during exercise). Along with the above noted return to a slower sinus rhythm, there was a significant reduction in the CTR by chest $x$-ray ( $53 \%$ precontrol vs $49 \%$ postcontrol, $P=0.02$ ).

Echocardiographic Measures of Ventricular Function. Figure 2 summarizes the improvement in cardiac function. Both the systolic and diastolic dimensions significantly decreased yielding an improved shortening fraction (mean $21 \%$ to mean $34 \%, \mathrm{P} \leq 0.05$ ). The two-dimensional echocardiographic ejection fraction, reflecting a more global measurement, also increased from a mean $36 \%$ to mean $50 \%$ following control of the tachycardia (P $\leq 0.01$ ). The mean heart rate corrected VCF increased from a mean of 0.62 to a mean of 1.20 circs/sec $(P=0.003)$. The EPSS/EDD, a measure independent of preload, was abnormal (i.e., greater than 0.2 -the 95 th percentile) in three of the five patients prior to treatment. Although one of these three remained $>95$ th percentile following arrhythmia control, all three were improved.
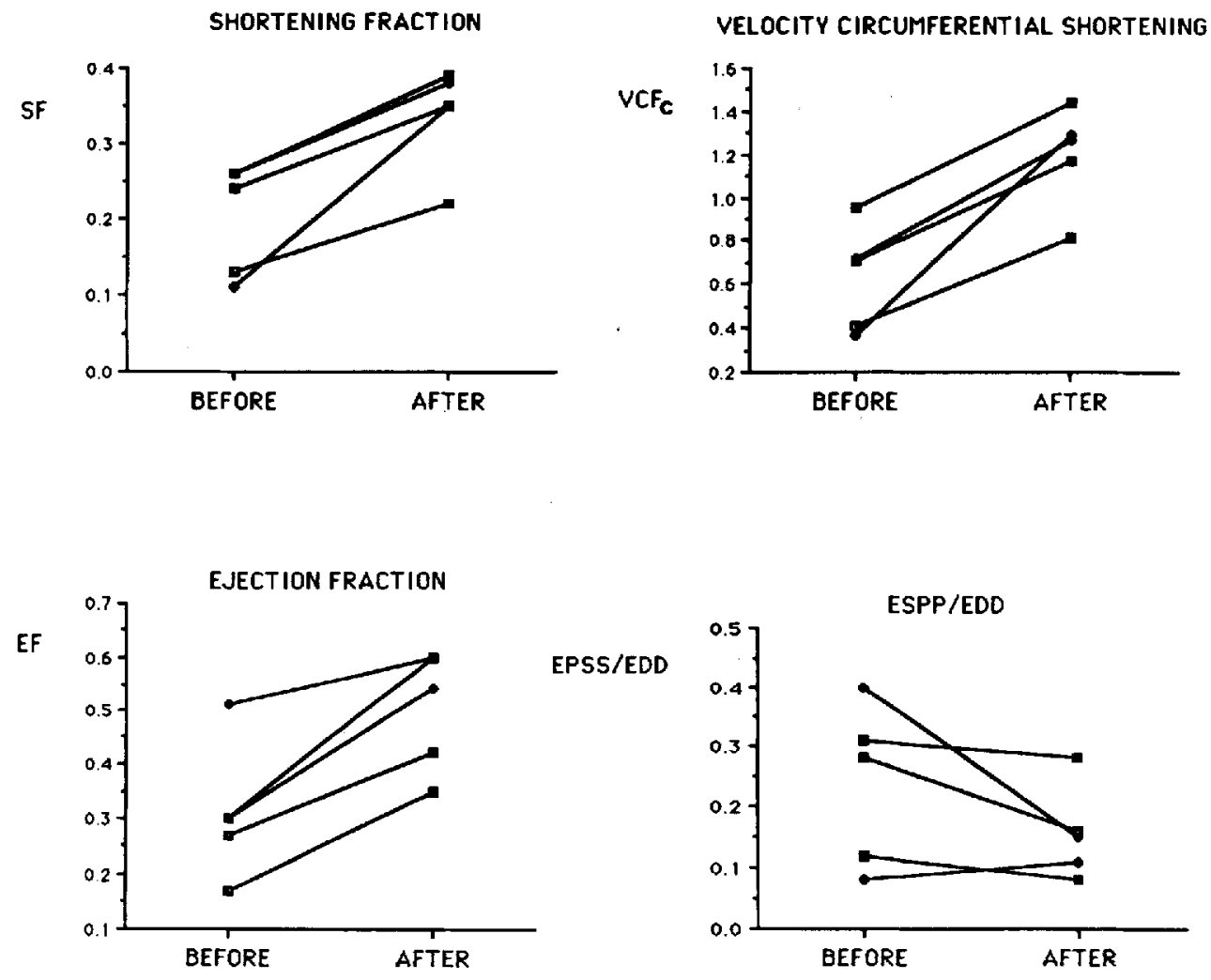

Figure 2. Echocardiographic measures of left ventricular function before and after final treatment in the five patients. $\mathrm{SF}=$ shortening fraction; $\mathrm{VCF}_{\mathrm{c}}=$ velocity of circumferential fiber shortening corrected for heart rate; $\mathbf{E F}=$ ejection fraction; EPSS/EDD $=$ E-point septal separation/end-diastolic dimension. 
Patient 2 is of particular interest (Fig. 3). Amiodarone successfully restored sinus rhythm but was discontinued because of hyperactivity possibly related to hyperthyroxinemia. Although flecainide replaced the amiodarone, the AAT resumed. After thyroid function was determined to be normal, amiodarone was restarted with return to sinus rhythm. Thus, during two separate treatment periods over a 6-month period, a direct relationship between the control of the tachycardia and normal echocardiographic measured cardiac function was observed.

Myocardial Biopsies. Light microscopic examination of the biopsies from the right ventricle showed no evidence for myocarditis or storage disease in any patient. Nonspecific myofibril hypertrophy and focal fibrosis that were within the range of normal were present in two patients (Table I). The atrial biopsy from patient 4 disclosed normal atrial tissue. In contrast, the atrial

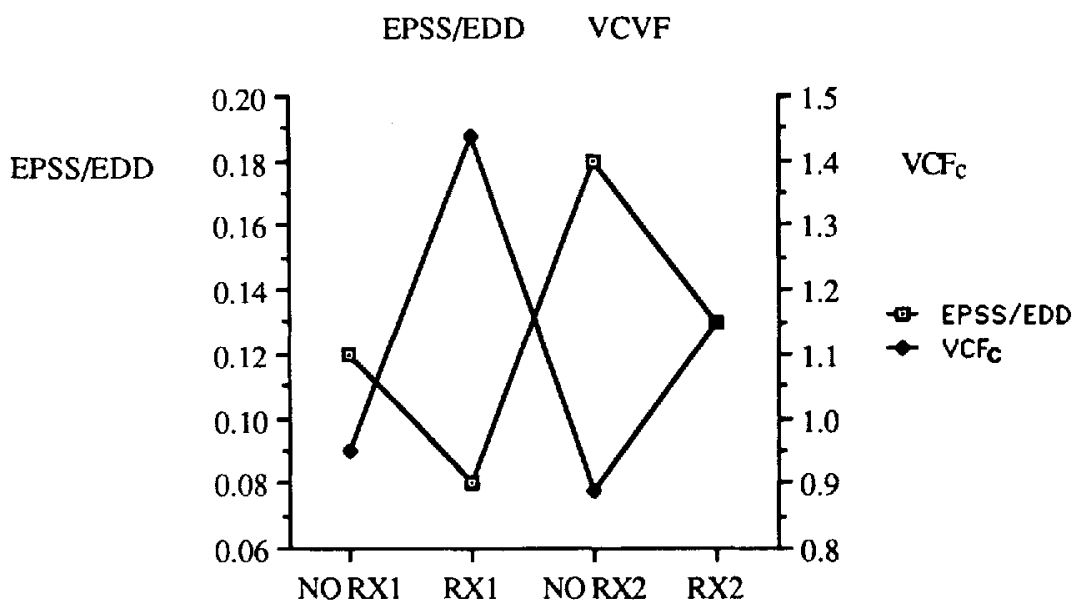

SHORTENING FRACTION/EJECTION FRACTION

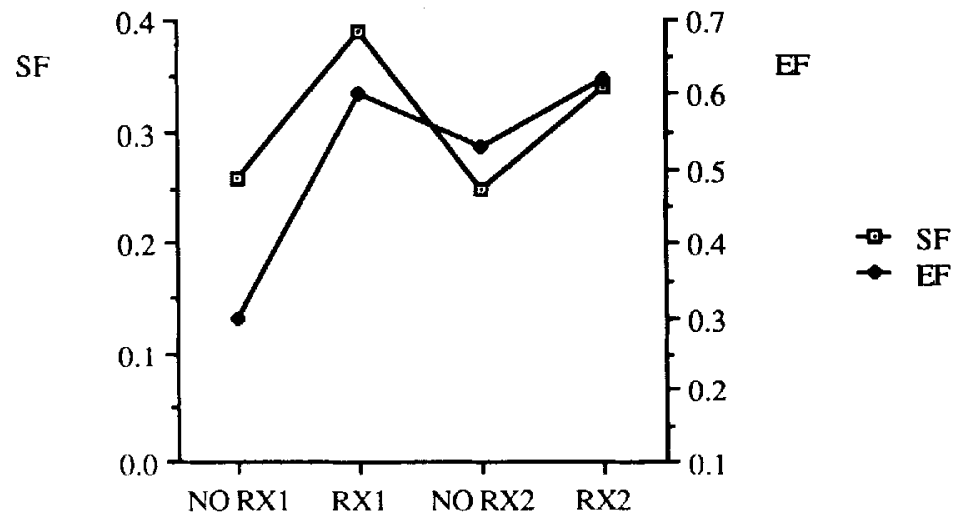

Figure 3. Echocardiographic measures of left ventricular function in patient \#1 during two trials of amiodarone. The interval between NORX 1 and RX 1 is 7 months; between RX1 and NORX2, 14 months; and between NORX2 and RX2, 4 months. EPSS/EDD = E-point septal separation/end-diastolic dimension; $\mathrm{VCF}_{\mathrm{c}}=$ velocity of circumferencial fiber shortening corrected for heart rate; $\mathrm{SF}=$ shortening fraction; $\mathrm{EF}=$ ejection fraction. 
tissue excised from patient 5 during surgery demonstrated Purkinje fiber-like tissue in specimens from the coronary sinus, the mapped origin of his tachycardia, as well as from the right atrial appendage (Table I).

Complications. No significant complications were encountered. Patient 2 required evaluation of his thyroid function because of the suspicion that he might be thyrotoxic. However, further thyroid studies excluded this possibility and amiodarone was resumed. Patient 4 experienced 2:1 heart block postoperatively, but permanent normal 1:1 conduction resumed within 5 days.

Follow-up. All patients except patient 4 are asymptomatic and virtually free of their tachyarrhythmia at mean 1.5 years following treatment. Following control of the tachycardia, three patients resumed full activity, and the other two have had a marked but not complete return to previous activity level. Patient 4 was recently hospitalized following a suicide attempt. Non-invasive evaluation at that time disclosed normal left ventricular function by echocardiogram, normal cardiac size on chest radiograph, normal exercise treadmill test, normal sinus rhythm during 12 of the 24 hours on Holter electrocardiography, and much less tachycardia that during the pretreatment period. Because of a complex social situation, further cardiac and arrhythmia evaluation was deferred.

\section{Discussion}

Our data are in accord with the observations of others that indicate that sustained automatic atrial tachycardia at only moderately elevated rates above normal (120-170 bpm) may produce significant impairment of cardiac function. Furthermore, our experience demonstrates that this impairment is associated with the appearance of symptoms. Finally, our experience confirms not only improved control of the tachycardia following pharmacological and/or surgical intervention, but also, as a result, significant recovery of cardiac function. ${ }^{6,7,13,14,26}$

The exact causal relationship between chronic atrial tachycardia and the development of a cardiomyopathic state has not been fully established. Recent studies ${ }^{27-29}$ have demonstrated that ventricular pacing of the canine heart at accelerated rates produces congestive heart failure in $2-3$ weeks. Although no direct evidence for a similar effect of chronic atrial pacing has been reported, the association of sustained supraventricular tachycardia and congestive heart failure in infants $^{30,31}$ as well as in older individuals ${ }^{4}$ has been recognized for several decades. The progression to a myopathy is less clear. Nonetheless, a number of reports $^{6,7,13,16-18,26}$ that indicate resolution of a dilated heart after control of supraventricular tachycardia, along with our experience, support these experimental data. Patient 3 represents a fortuitous clinical experiment supporting those observations. This patient demonstrated over a 6-month period a direct relationship between control of the tachycardia and improvement in ventricular function. Further, the observation from our two operated patients that the return of cardiac function was not instantaneous suggests that the observed change in the echocardiographic measures of ventricular function are not simply a function of heart rate but reflect genuine improvement in ventricular performance.

Previous reports ${ }^{14,32,33}$ have suggested Purkinjelike or mesenchymal type tumors causing automatic tachycardia as well as other complex arrhythmias; on the other hand atrial biopsies in 10 other patients with sustained $\mathrm{AAT}^{6,12,15,17,19}$ were nonspecific. Patient 5 had Purkinje-like fibers excised from the area of tachycardia focus. Interestingly, similar cells were found in his incidentally discarded right atrial appendage taken for cannulation. These abnormal mesenchymal cells/Purkinje fibers argue against a cardiac muscle abnormality as the cause of the AAT and lead to the possibility of multiple subclinical abnormal cells in patients with automatic atrial tachycardia, giving rise to the possibility of late recurrence. In contrast, the atrial tissue excised from Patient 4 failed to disclose unusual cells, perhaps suggesting an incomplete ablation of her ectopic focus and, thus, explaining, in part, her less successful result. The nonspecific right ventricular biopsy material from our three patients, along with the five reported by others, ${ }^{6}$. underscores the absence of a primary ventricular abnormality as the proximate cause of the observed impairment in cardiac function.

Conventional therapy is rarely effective. Digoxin alone failed to control the SVT in four of our 
five patients; the addition of beta blockade in two patients was also unsuccessful. Both patients who received amiodarone converted to sinus rhythm. Thus, similar to other reports, ${ }^{34,35}$ our experience suggests that no single therapeutic regimen emerges as the clear treatment of choice. Because of the infrequency of this disorder, its variable natural history, including documented spontaneous remission of the tachycardia ${ }^{34,35}$ and the nonrandom use of the different forms of therapy, a single optimal treatment for all patients will probably not be forthcoming. Thus, a step-wise approach may be prudent. In the absence of symptoms and with no evidence of impaired ventricular function, therapy may not be necessary. Because control of the tachycardia will restore ventricular function, with increasing improvement over time, noninvasive evidence for decreased ventricular function warrants treatment. New antiarrhythmic medications, including flecainide, encainide, ethmozine, and amiodarone, ${ }^{8-11}$ along with the development of electrophysiological-cryosurgical techniques ${ }^{12-18}$ offer several avenues for management. However the recent experience with flecainide and encainide ${ }^{36}$ underscores the need for a careful weighing of the risks of treatment (as well as no treatment) along with the benefits expected before initiating unexplored pharmacological therapy.

\section{Conclusions}

We conclude that AAT may be causally linked to the development of cardiomyopathy. Poorly controlled AAT may present clinically as congestive heart failure, or more subtly, with impairment of ventricular function prior to the onset of overt failure. In the experience reported herein, as well as those of others, aggressive management results in resolution of the SVT, symptomatic improvement, and normalization of ventricular function. Because AAT is a treatable arrhythmia, any child presenting with symptoms, signs, and echocardiographic evidence of cardiomyopathy should be carefully evaluated by ECG, 24-hour ambulatory ECG, and, if necessary, electrophysiologic studies. Treatment should be instituted if either symptoms or the noninvasive findings of decreased ventricular function are present.

\section{References}

1. Gillette PC. The mechanism of supraventricular tachycardia in children. Circulation 1976; 54:133-139

2. Campbell RM, Dick M, Rosenthal A. Cardiac arrhythmias in children. Am Rev Med 1984; 35:397-410.

3. Keane JF, Plauth WH, Nadas AS. Chronic ectopic tachycardia of infancy and childhood. Am Heart J 1972; 84:748-757.

4. Weiss HB, McGuire J. Ectopic tachycardia, auricular in origin, of unusual duration. Am Heart J 1936; 12:585591.

5. Hay JD, Keidan SE. Persistent ectopic auricular tachycardia in children. Br Heart J 1952; 14:345-349.

6. Parker DL, Gust HB, Seth JW, et al. Tachycardia-induced cardiomyopathy: A reversible form of left ventricular dysfunction. Am J Cardiol 1986; 57:563-570.

7. Kugler JE, Baisch SO, Cheatham JP, et al. Improvement of left ventricular dysfunction after control of persistent tachycardia. J Pediatr 1984; 105:543-548.

8. Evans EL, Garson A Jr, Smith RT, et al. Ethmozine: A promising drug for automatic atrial ectopic tachycardia. Am J Cardiol 1987; 60:83F-86F.

9. Kunze KP, Kuck KH, Schluter M, et al. Effect of Encainide and Flecainide on chronic atrial tachycardia. J Am Coll Cardiol 1986; 7:1121-1126.

10. Berns E, Rinkenberger RL, Jeang M, et al. Efficacy and safety of flecainide acetate for atrial tachycardia or fibrillation. Am J Cardiol 1987; 59:1337-1341.

11. Coumel P, Fidelle J. Amiodarone in the treatment of cardiac arrhythmias in children: One hundred thirty-five cases. Am Heart J 1980; 100:1063-1069.

12. Wyndham CRC, Arnsdorf MF, Levitsky S, et al. Successful surgical excision of focal paroxysmal atrial tachycardia: Observations in vivo and vitro. Circulation 1980 62:1365-1372.

13. Olsson SB, Blomstrom P, Sabel KG, et al. Incessant ectopic atrial tachycardia: Successful surgical treatment with regression of dilated cardiomyopathy picture. Am J Cardiol $1984 ; 53: 1465-1466$

14. Josephson ME, Spear JF, Harken AH, et al. Surgical excision of automatic atrial tachycardia: Anatomic and electrophysiologic correlates. Am Heart J 1982; 104:10761085

15. Iwa $T$, Ichihashi $T$, Hashizume $Y$, et al. Successful surgical treatment of left atrial tachycardia. Am Heart J 1985; 109:160-162.

16. Ott DA, Garson A, Cooley PA, et al. Definitive operation for refractory cardiac tachydysrhythmias in children. $\mathrm{J}$ Thorac Cardiovasc Surg 1985; 90:681-689.

17. Frank G, Baumgart D, Klein H, et al. Successful surgical treatment of focal atrial tachycardia-a case report and review of the literature. J Thorac Cardiovasc Surg 1986 $34: 398-402$.

18. Gillette PC, Smith RT, Garson A Jr, et al. Chronic supraventricular tachycardia, a curable cause of congestive cardiomyopathy. J Am Med Assoc 1985; 253:391-392.

19. Giorgi LV, Hartzler GO, Hamaker WR. Incessant focal atrial tachycardia: A surgically remediable cause of cardiomyopathy. J Thorac Cardiovasc Surg 1984; 87:466473.

20. Gillette PC, Wamplec PL, Garson A Jr, et al. Treatment of atrial automatic tachycardia by ablation procedures. J Am Coll Cardiol 1985; 6:405-409.

21. Davis J, Scheinman MM, Ruder MA, et al. Ablation of cardiac tissues by an electrode catheter technique for 
BROMBERG, ET AL.

treatment of ectopic supraventricular-tachycardia in adults. Circulation 1986; 74:1044-1053.

22. Borggrefe $M$, Breithardt $G$. Ectopic atrial tachycardia after transvenous catheter ablation of a posteroseptal accessory pathway. J Am Coll Cardiol 1986; 8:441 -445.

23. Goldreyer BN, Gallagher JJ, Damato AN. The electrophysiologic demonstration of atrial ectopic tachycardia in man. Am Heart J 1973; 85:205-215.

24. Scheinman MM, Debal B, Hollenberg M. Electrophysiologic studies in patients with persistent atrial tachycardia. Circulation 1974; 50:266-273.

25. Gillette PC, Garson A Jr. Electrophysiologic and pharmacologic characteristics of automatic ectopic atrial tachycardia. Circulation 1977; 56:571-575.

26. Gallagher JJ. Tachycardia and cardiomyopathy: The chicken-egg dilemma revisited. J Am Coll Cardiol 1985; 6:1172-1173.

27. Coleman HN, Taylor RR, Pool PE, et al. Congestive heart failure following chronic tachycardia. Am Heart J 1971; 8:760-798.

28. Wilson JR, Douglas P, Hickey WF, et al. Experimental congestive heart failure produced by rapid ventricular pacing in the dog: Cardiac effects. Circulation 1987; 75:857-867.
29. Armstrong PW, Stopps TP, Ford SE, et al. Rapid ventricular pacing in the dog: Pathophysiologic studies of heart failure. Circulation 1986; 74:1075-1084.

30. Silverman JJ, Race OM. Paroxysmal tachycardia with a ventricular rate of 365 per minute. Am Heart J 1949; 37:1139-1143.

31. Nadas AS, Daeschner CW, Roth A. Paroxysmal tachycardia in infants and children. Pediatrics 1952; 9:167-181.

32. James TN, Beeson CW, Sherman EB, et al. De Subitaneis Mortibus, XIII. Multifocal Purkinje cell tumors of the heart. Circulation 1975; 52:333-344.

33. Rossi L, Piffer R, Turolla E, et al. Multifocal Purkinje-like tumor of the heart: Occurrence with other anatomic abnormalities in the atrioventricular junction of an infant with junctional tachycardia, Lown-Ganong-Levine syndrome, and sudden death. Chest 1985; 87:340-345.

34. Mehta AV, Sanchez GR, Sacks EJ, et al. Ectopic automatic atrial tachycardia in children: Clinical characteristics, management, and follow-up. J Am Coll Cardiol 1988; 11:379-385.

35. Koike K, Hesslein PS, Finlay CD, et al. Atrial automatic focus tachycardia in children. Am J Cardiol 1988; 61:1127-1130.

36. CAST Investigators. The cardiac arrhythmia suppression trial. N Engl J Med 1989; 321:406-412. 